\title{
Limites e Desafios para o Estudo da Intervenção Profissional em Educação Física a partir da Noção de Competência
}

Jeane Barcelos Soriano Pedro José Winterstein

\begin{abstract}
Resumo: Colocamos como objetivos desse trabalho discutir e problematizar a noção de competência e os elementos complexos vinculados à intervenção do profissional de educação física no ambiente não escolar. Para isso, foram trazidos alguns apontamentos sobre a cautela que se deve ter ao lidar com a noção de competência em diversos aportes teóricos. O caráter transitivo que reveste as intervenções profissionais, de maneira geral, e em educação física, especificamente é, sem dúvida, o mais provocativo desafio. Nesse sentido, para compreender aquilo que compõe as intervenções/ações profissionais em educação física, ou seja, o conhecimento "formalizado", as estratégias de ação e as representações, faz-se necessário reconhecer a natureza multidimensional implicada nas respostas profissionais. Finalmente, podemos considerar que o emprego da noção de competência pode permitir o discernimento daquilo que orienta o processo de tomar decisão do profissional de educação física, inclusive no entendimento da ênfase discricionária de suas decisões. Palavras-chave: Competência. Prática profissional. Educação física.
\end{abstract}

\section{Elucidando o Problema}

As abordagens e discussões sobre o que deveria constituir o conhecimento formalizado e a educação profissional, bem como, sobre as características de um trabalho competente, sempre foi, junto a diversas áreas, objeto de grandes embates e de pouco consenso (BURRAGE,1996; TORSTENDAHL, 1996). Não seria diferente junto à Educação Física, cujo discurso de incipiência tem se esgotado como justificativa de poucas propostas ou estudos sobre os elementos de síntese e intervenção profissional. Ao mesmo tempo, é preciso reconhecer que a investigação e reflexão so-

Movimento, Porto Alegre, v.12, n. 01, p. 175-195, janeiro/abril de 2006. 
bre temas ligados à intervenção profissional são dispendiosas e consomem grande quantidade de tempo, dedicação de pesquisadores e, necessariamente, devem resultar do trabalho contíguo aos profissionais atuantes (LAWSON, 1990; BETTI, 1996).

Não obstante, importantes reflexões e ensaios têm sido publicados sobre os pontos críticos da educação profissional, área de conhecimento e, até, desempenho profissional. Porém, tais apontamentos têm em suas referências ou citações poucos ou quase nenhum estudo de campo, a partir dos quais realmente poder-se-ia constatar as implicações ou resultados de uma determinada forma de agir, fosse em função da educação profissional equivocada ou da imaturidade da área, do ponto de vista acadêmico (LAWSON, 1990; RANGEL-BETTI, 1998).

A esse respeito, caberia questionar se não há uma tendência em convergir todas as características e problemas da intervenção profissional em educação física para o nosso modus operandi de ver os fenômenos da área. Em outras palavras, é preciso observar se não estamos "examinando" os acontecimentos com as lentes e instrumentos inadequados, o que pressuporia transferir para os profissionais ou para as situações de intervenção, de maneira geral, as preocupações e questionamentos que acompanham a nossa vida acadêmica, como pesquisadores e docentes do meio universitário, os quais, a despeito de possíveis inter-relações, muitas vezes, não são originados, amadurecidos e debatidos, nem junto aos profissionais, nem no contexto no qual as ações são construídas.

Nesse sentido, o que acaba acontecendo é que somos levados a enxergar na ação de outrem, no caso os profissionais de educação física, aquilo que falta para o nosso próprio domínio instrumental e acadêmico. O resultado parece, então, se distanciar operacionalmente, tanto do entendimento do que realmente acontece nos contextos de atuação, como também, da proposição de soluções dos problemas lá originados, dificultando, por sua vez o surgimento de linhas de investigação ou utilização de encaminha-

Movimento, Porto Alegre, v.12, n. 01, p. 175-195, janeiro/abril de 2006. 
mentos metodológicos que levem em consideração as peculiaridades de cada situação de intervenção profissional.

Por fim, se por um lado toda a produção acadêmico-científica da educação física dos últimos anos permitiu visualizar, com outras referências, importantes problemas da área, inclusive da intervenção, por outro, precisamos estar atentos e transformar essa produção num ponto de reflexão, mas não necessariamente "o" ponto pelo qual todo e qualquer conhecimento sistematizado sobre a intervenção não poderá prescindir, em hipótese alguma (LAWSON, 1995). Especialmente porque alguns fatores não podem ser explicados pelo caráter mais ou menos acadêmico que uma área possa vir a ter, nem sequer aprimorados pela extensão e implicação do conteúdo da educação profissional (FREIDSON, 1998).

Por isso, entendemos ser urgente e necessário para quem se dedica às questões de educação e intervenção profissional, especialmente em educação física, o entendimento de como sucedem: (a) a organização das tarefas e do trabalho realizado individualmente e em grupo; (b) as peculiaridades do tipo de respostas profissionais, a partir da configuração do grupo ao qual pertence o profissional; (c) a visão que o profissional de educação física possui acerca da importância e significado do trabalho que realiza no contexto social no qual está inserido, junto aos usuários e pares; (d) as representações do papel desempenhado pelo profissional de educação física, enquanto inserido em uma determinada área de intervenção; (e) as características e modificações que vão se realizando junto ao conhecimento empregado pelo profissional de educação física no decorrer de suas intervenções profissionais.

Como a identificação de uma intervenção competente é estabelecida entre o conhecimento e a situação, inúmeras vezes, o pesquisador acaba sendo atraído pela classificação dos conhecimentos ou construção de tipologias, resultando uma secundarização do que, realmente, deveria ser revelado, ou estar à prova, que são: as referências da relação entre conhecimento e ação (TANGUY, 1997).

Movimento, Porto Alegre, v.12, n. 01, p. 175-195, janeiro/abril de 2006. 
A problematização da noção de competência e sua utilização nos oferecem alguns elementos para apreciação e reconhecimento de suas especificações, instrumentalizando a observação das possibilidades de combinação industriosa ${ }^{1}$ que o indivíduo realiza entre os componentes que detém, durante uma dada intervenção profissional.

Por outro lado, concordamos com Schwartz (1998), quando afirma que há uma ênfase e preocupação "hipertrofiada" com a competência, por parte de diversos segmentos da sociedade, trazendo como conseqüência estudos fragilizados pelo enfoque equivocado ou mesmo pela não possibilidade de extensão a um tratamento multidisciplinar. Ainda segundo esse autor, ao mesmo tempo, seria uma irresponsabilidade criticar a preocupação de estudiosos em avaliar as competências das pessoas no trabalho, "[...] uma vez que nenhum projeto humano escapa a essa regra [...]" (p.102). Negar isso, com intuito de superar o discurso ingênuo, implica beirar a demagogia.

Proporemos, então, como objetivo desse trabalho discutir e problematizar a noção de competência e os elementos complexos vinculados à intervenção do profissional de educação no ambiente não escolar.

\section{Noção de Competência em discussão: alguns elementos para aplicação no estudo da intervenção profissional}

Em diversos países da Europa e América tem havido, por parte de autoridades ligadas à instituições educacionais, empresas e associações de grupos profissionais, uma acentuada preocupação com a noção ou idéia de "competência profissional". Apesar

${ }^{1}$ Com base nas notas de Schwartz (1998), entendemos que industrioso(a) é um adjetivo empregado pelo autor exatamente para qualificar ou identificar o "uso de si" que o indivíduo faz em situações de escolha, nas quais deve arbitrar entre valores diferentes e, às vezes até mesmo, contraditórios. Portanto, esse "uso de si" tem de ser habilidoso e perspicaz, ou seja, industrioso, no enfrentamento das situações de trabalho.

Movimento, Porto Alegre, v.12, n. 01, p. 175-195, janeiro/abril de 2006 
dessa preocupação ter sido mais pressionada pelo resultado do processo conhecido por "reestrutração produtiva" do setor industrial e da economia globalizada (DESAULNIERS, 1998; MANFREDI, 1998), muitas de suas referências foram importadas, modificadas e aplicadas no setor educacional e profissional.

Ropé \& Tanguy (1997) chamam a atenção para o fato de não haver uma definição precisa e conclusiva sobre o que deveria dizer respeito à competência. Justificam que isso se deve, sobretudo, pelos diversos usos que se faz da noção de competência em diversas áreas, como economia, trabalho, educação e formação profissional. Consideram ainda que essa noção tende a tomar o espaço de outras noções que eram dominantes em diversas áreas, como por exemplo, a de "saberes e conhecimentos" na educação e de "qualificação" no universo do trabalho (DESAULNIERS, 1998). Portanto, "[...] é necessário reconhecer que a plasticidade desse termo é um elemento da força social que [o] reveste e das idéias que veicula [...]" (ROPÉ \& TANGUY, 1997, p.16).

Cabe ressaltar que a origem e amadurecimento do uso e das reflexões sobre competência partem em grande medida de economistas, sociólogos, psicólogos e pedagogos ligados ao estudo e pesquisa junto ao setor do operariado fabril. Sendo que a impressão que temos é que os demais setores que se apropriaram e utilizaram a noção de competência, o fizeram muito mais pelo fato de ser um termo no qual se opera algum tipo de representação, portanto, um certo grau de comunicação. Nesse caso, os usos que se faz do termo se aproximam muito mais do senso comum, do que de algo constituído e refletido sistematicamente.

Quando consideramos a noção de competência e sua polissemia ${ }^{2}$ como condição inerente, assumimos que haverá sempre

\footnotetext{
${ }^{2}$ A polissemia é um fenômeno comum nas línguas naturais, são raras as palavras que não a apresentam; difere da homonímia por ser a mesma palavra, e não, palavras com origen diferentes que convergiram foneticamente; as causas da polissemia são: 1) os usos figurados, por metáfora ou metonímia, por extensão de sentido, analogia etc.; 2) empréstimo de acepção que a palavra tem em outra língua. (HOUAISS, 2001. Dicionário eletrônico)
}

Movimento, Porto Alegre, v.12, n. 01, p. 175-195, janeiro/abril de 2006. 
diferenças consideráveis no conteúdo de sua definição, conforme nuanças de cada área de atuação, seja em relação às suas respectivas tarefas e valores ou, ainda, matizes epistemológicos de cada campo de conhecimento. De qualquer maneira, sejam quais forem as referências desse assunto para o estudo de uma intervenção profissional, elas serão circunstancialmente diferentes daquelas utilizadas para pesquisa, análise e reflexão do trabalho operariado, que é objeto de grande parte da literatura sobre competência.

Junto a isso, então, devemos assumir também que o meio no qual os profissionais, em geral, e o profissional de Educação Física, em particular, devem operar uma determinada intervenção é contingente e vinculado a espaços sócio-culturais. Portanto, para Manfredi (1998) algumas conotações relativas à noção de competência precisam ser examinadas com cautela, pois são pautadas, exclusivamente, em princípios de racionalidade técnica, constituída muitas vezes a partir de referências comportamentalistas (PATTO, 1981, citada por MANFREDI, 1998). Nesse caso, o que de certa forma, se está procurando são medidas universalizadas e padrões a serem seguidos, encobertos por subterfúgios como habilidades gerais, referências de conduta e determinadas experiências individuais, as quais acabam servindo como parâmetros de exclusão, deixando de fora habilidades outras, que não aquelas colocadas nessas referências.

Stroobants $(1997,1998)$ destaca que muitos dos estudiosos concordam sobre a complexidade e extensão das manifestações de competência durante o processo de intervenção, no entanto, pontua que não há consenso no momento de se definir os conhecimentos observados. Para essa autora, mais importante do que adotar categorias de saberes e de competências como fatores explicativos, é preciso tomá-las como objetos a explicitar.

Para o aprimoramento e estudo da competência, então, parece ficar clara, segundo Meghnagi (1998), a necessidade de se avançar da idéia de meramente definir ou demarcar tarefas, procurando

Movimento, Porto Alegre, v.12, n. 01, p. 175-195, janeiro/abril de 2006. 
uma correlação instaurada mecanicamente com conhecimentos que, supostamente, as embasariam:

[...] faz-se necessário para caracterizá-la desenvolver a capacidade descritiva, e não prescrita, em relação a fenômenos em que os aspectos individuais, de grupo e de contexto se entrelaçam fortemente, envolvendo variáveis sociais e psicológicas tais para condicionar, em seu agir conjunto, as formas de exercício de uma determinada atividade (MEGHNAGI, 1998, p.52).

Até porque "[...] antes de propor dispositivos e procedimentos de formação, temos de compreender melhor a gênese dos esquemas, das competências e dos saberes subjacentes às práticas" (PERRENOUD, 2001, p.16). Tratar desse aspecto, pelo menos para nós, é iniciar uma trilha por um caminho insólito, pela forte presença do senso-comum no modo de ver a noção de competência, até mesmo no meio acadêmico e universitário. Daí decorrendo o risco de uma supersimplificação que não se difere, nem acrescenta muito aquilo que já temos sobre o assunto, mas que por outro lado, pode exercer uma grande atração se o pesquisador mantiver uma postura arrogante ao acrescentar algum conceito, ou "estratégia" de análise, tentando forçar que um fenômeno, mutável e fluido, seja colocado dentro de definições, listagens e "modos de ver", originados exclusivamente da racionalidade científica (TARDIF \& GAUTHIER, 2001)

Considerada como categoria de análise, construída socialmente (Ropé \& TANGUY, 1997; DESAULNIERS, 1997, 1998), a abordagem dos saberes associados às intervenções profissionais se caracteriza com referência à sua valorização social (STROOBANTS, 1997). A partir dessa perspectiva, é possível, inclusive, considerar que a diferenciação entre perícia especializada e habilidade comum não está necessariamente no tipo ou propriedade do raciocínio empregado, "[...] mas no estatuto social do conhecimento em questão [...]". O que explica a causa de grupos

Movimento, Porto Alegre, v.12, n. 01, p. 175-195, janeiro/abril de 2006 
profissionais buscarem, na maior parte do tempo, “[...] resolver um problema de reconhecimento das formas [...]" que empregam para intervir num determinado ambiente (STROOBANTS, 1998, p.34). Em outras palavras, o problema de reconhecimento das formas perpassa a necessária inserção social do tipo de conhecimento a ser empregado por um profissional.

Nesse caso, a organização da noção de competência em torno dos componentes "saber"; "saber fazer", "saber ser" não dá conta de identificar e denotar a amplitude e complexidade que estão por trás, mesmo, de tarefas consideradas simples ou rotineiras. Enfim, "os processos pelos quais as competências transmitem-se, adquirem-se, diferenciam-se, estruturam-se são precisamente o que mais falta nesses estudos dos saberes" (STROOBANTS, 1998, p.94).

De qualquer forma, o que parece ficar demarcada é a estreita relação da noção de competência com a avaliação de como o indivíduo realiza a tarefa, direcionando-se a atenção para identificar que esquemas adota durante suas intervenções, o grau de autonomia, o tipo de combinação de conhecimentos utilizados, a reconstrução dos conhecimentos a partir dos esquemas interiorizados ou já existentes etc., ou seja, procurando explicitar as " [...] representações das práticas e do mundo social do qual fazem parte as competências mobilizadas [...]" (PERRENOUD, 2001, p.21).

Sem esquecer que, tanto na construção, como na caracterização da competência profissional, Meghnagi (1998) destaca que estão vinculados múltiplos fatores, tais como: (a) a aquisição de conhecimentos, tanto escolarizados, como também, por meio de processos informais de aprendizagem que podem acontecer em momentos e espaços distintos; (b) orientações de valores possibilitando ou não o suporte para inovações; (c) pertencimento a uma comunidade profissional; (d) a constituição e apropriação de um saber a partir da própria situação de aplicação.

O que temos, então, quando observamos o agir profissional, 
são elementos tácitos que interferem na intervenção, mas que são muito difíceis de descrever, seja por não possuirmos instrumentos ou estratégias para mapeá-los, seja porque nem mesmo o profissional tem como reconhecer, ou quer reconhecer tais aspectos. Em síntese, são "[...] faculdades ou competências que nos permitem agir mesmo quando não é possível realizar uma ação totalmente racional" (PERRENOUD, 2001, p.24).

Becher (1996) realizou um estudo para identificar como os profissionais se organizam diante das demandas por novos tipos de competência. Assim, observou que fatores contextuais, como por exemplo, políticas locais, interferência do tipo de gerenciamento e negócios, fatores econômicos, geração de novas técnicas, mudanças tecnológicas e informacionais podem influenciar a natureza do conhecimento profissional, implicando muitas vezes reestruturações das próprias profissões - em outras palavras, algumas tarefas ou modos de realização das intervenções dos grupos profissionais podem ser criados ou mesmo desaparecerem.

O mesmo autor reporta-se aos modos de aprendizagem profissional mais usuais destacados pelos componentes dos grupos profissionais que pesquisou, são eles: cursos e conferências, as próprias interações profissionais, a rede de relações do próprio trabalho ou especialidade, consulta aos peritos ou mais experientes, pesquisa pessoal, aprendizagem, enquanto realiza a tarefa, aprendizagem por meio de instrução relacionada à tarefa e a outro profissional.

Freidson (1998), reforça fatores multi-influenciadores nas configurações das respostas profissionais, principalmente os processos de interação e organização informal: "A interação entre trabalhadores e entre trabalhadores e supervisores determina também o modo de conceber as tarefas, quem deve realizá-las e como devem ser realizadas" (p.94)

Outrossim, as lutas jurisdicionais entre grupos profissionais no próprio local de trabalho acabam também interferindo no pro-

Movimento, Porto Alegre, v.12, n. 01, p. 175-195, janeiro/abril de 2006 
cesso de construção das intervenções profissionais; de maneira que limitações rígidas e legalmente colocadas têm suas fronteiras negociadas e renegociadas no cotidiano das intervenções profissionais, trazendo conseqüências para as definições das tarefas e até mesmo para identidade do profissional atuante (FREIDSON, 1998; SORIANO, 2004).

Como pudemos verificar, mais uma vez, não é possível explicar a competência profissional a partir de atuações constantes, como se os problemas fosse relativamente homogêneos e idênticos entre si. Podemos conferir, então, que ela:

Caracteriza-se, sobretudo, pela variedade teoricamente ilimitada de questões e de imprevistos a serem enfrentados adequando $e$ reelaborando o saber que se possui. Esta variedade é neste sentido flexivel, exigindo um conjunto complexo de conhecimentos e habilidades (MEGHNAGI, 1998, p.67).

Segundo Desaulniers (1997), essa possibilidade de reelaboração de "saberes" não está restrita aos tipos de qualificação, entendidas aqui como essencialmente formais ou escolarizadas. As manifestações competentes são muito mais abrangentes, diversificadas e complexas, pois é preciso observar a relação entre o repertório cognitivo e as referências de valor do indivíduo a qual, consoante a Meghnagi (1998), evidencia-se como referência para discernir as possibilidades de seleção que são realizadas durante o exercício profissional. Daí, o mesmo autor considerar limitante, tanto a atribuição de competência apenas ao domínio de componentes lógico-científicos, como também atrelar sua avaliação ao outro extremo, da inventividade ou iniciativa, implicando a capacidade, "quase inesgotável", de encontrar soluções novas.

Desse modo, é importante observar que:

A aquisição do conhecimento não é resultado
de um processo cumulativo e mecânico, em que
os conteúdos transmitidos são acolhidos de ma-

Movimento, Porto Alegre, v.12, n. 01, p. 175-195, janeiro/abril de 2006. 
neira idiossincrática pelo sujeito que aprende. Mas sim resultante [...] de percursos complexos de se compreender, dentre os quais é necessário considerar os contextos de vida e de trabalho, em que o locus de experiência e de saber são estruturados, absorvidos e elaborados (MEGNHAGI, 1998, p.75).

Não há como definir precisamente os saberes ou habilidades demandadas durante uma ação competente, isso por conta da grande flexibilidade de sua construção, influenciada, por sua vez, pela potencial e ampla variedade de percursos profissionais (MEGNHAGI, 1998). Portanto, para a análise do processo de evolução do saber necessário ao trabalho, ou seja, para o estudo da competência, "[...] parece mais produtivo tender a refletir sobre as necessidades de conhecimentos mais do que tender para uma análise das demandas formativas" (MEGNHAGI, 1998, p.81).

Diante desse quadro, caberia colocarmos em questão se é possível estudar e analisar as intervenções profissionais a partir da referência ou da noção de competência. Nesse caso, corroboramos o ponto de vista de Perrenoud (2001), quando coloca que o grande desafio para os pesquisadores está em assumir e operacionalizar a capacidade de tomar consciência, de explicitar e descrever, sem julgar, a utilização desses elementos tácitos por parte dos pesquisados. Nesse caso, o resultado mais importante desse processo é perceber que o aumento da competência para realização de uma intervenção, não está ligado apenas a uma racionalidade integral, crescente, como querem alguns; mas, sim, no entendimento e na proposição da necessária junção entre razão e subjetividade.

Os elementos complexos das intervenções profissionais em Educação Física no universo não escolar

O estudo e o enfoque de pesquisa nas intervenções profissionais em educação física, mais precisamente daqueles atuantes na

Movimento, Porto Alegre, v.12, n. 01, p. 175-195, janeiro/abril de 2006. 
área não escolar e do seu trabalho, toma um contorno especial, por três motivos, a saber:

(a) um deslocamento do foco de observação na realização da pesquisa, que procura colocar as articulações e mobilização de recursos, que o profissional detém, no centro da análise, em vez de avaliar se há ou não domínio suficiente de qualquer de saber essencialmente formalizado.

(b) a recenticidade da inserção no mercado de trabalho de bacharéis em educação física, supostamente mais bem preparados para atuar no universo de trabalho não escolar, para o qual, a demanda existe desde os primórdios da formação profissional na área. No entanto, ainda não conseguimos apontar as implicações dessa especificidade da preparação e as possíveis conseqüências junto às intervenções.

(c) começamos a ter a sensação de uma quase saturação de estudos acerca da formação profissional e, contraditoriamente, sem um impacto muito significativo na maior parte da configuração dos cursos de graduação da área. Isso, provavelmente, vem se dando em decorrência do distanciamento dos objetos desses estudos dos campos de intervenção, seja por questões metodológicas, ou vieses paradigmáticos. Além de, geralmente, procurarem em suas justificativas serem norteados pela importância e necessidade de adaptação de uma Área de Conhecimento academicamente mais tradicional para intervenção.

Tani (1996) menciona a estipulação de linhas de pesquisa para investigação de temas profissionalizantes, cujos resultados fossem colocados diretamente à disposição dos cursos de educação profissional. Se por um lado, o autor realiza uma crítica que merece ser considerada, com relação às poucas investigações ou estudos empíricos por parte daqueles que estudam aspectos da preparação e intervenção, por outro, deixa em aberto quais seriam os "temas profissionalizantes" a serem estudados ou quais seriam os seus constituintes.

Movimento, Porto Alegre, v.12, n. 01, p. 175-195, janeiro/abril de 2006 
Um possível encaminhamento seria reconhecer e conhecer as especificidades das tarefas e intervenções profissionais em educação física (RANGEL-BETTI, 1998). Recorremos mais uma vez a Lawson (1990, p.171) para evidenciar algumas fontes de variabilidade que a organização do trabalho profissional em educação física pode vir a sofrer: (a) receptividade e adoção de tecnologias relacionadas ao trabalho; (b) extensão da especialização do trabalho; (c) culturas e sub-culturas organizacionais; (d) táticas de socialização organizacional e sistemas de comunicação; (e) relações para ampliar o ambiente organizacional: autonomia organizacional versus heteronomia, competição com outras organizações prestadoras de serviços; (f) características dos clientes: homogeneidade versus heterogeneidade, prestação de serviços individualizados versus atendimento em grupos; composição de gênero, socioeconômica e racial; receptividade e aceitação das normas; poder formal e informal; (g) sistemas de apoio organizacional: público versus privado, organizações não governamentais versus organizações financeiras; (h) gerenciamento organizacional: sua estrutura, estilo e prerrogativas; (i) objetivos do programa e sistemas de avaliação: objetivos singulares ou múltiplos, objetivos reais ou procedimentais, sistemas de responsabilidades.

Mesmo colocados de maneira geral, esses aspectos nos dão uma dimensão da complexidade de variáveis organizacionais e de sua combinação, as quais estão submetidas às intervenções profissionais em educação física. Então, o principal problema em centrar exclusivamente as análises, descrições e compreensões no tipo de razoamento científico, é que o trabalho profissional em Educação Física como pertencente à organização social do trabalho, compartilha de suas variáveis, tais como divisão do trabalho, características da clientela, sistemas de suporte, sistemas de recompensa etc. Esses aspectos são, muitas vezes, ignorados no momento da realização ou sistematização do conhecimento advindo da pesquisa.

Movimento, Porto Alegre, v.12, n. 01, p. 175-195, janeiro/abril de 2006. 
O que acaba acontecendo é o fato do próprio profissional, à medida que vai vivenciando e experimentando algumas situações, constrói um conjunto de referências para suas respostas, não necessariamente, advindas do conhecimento científico (LAWSON, 1990; LOVISOLO, 1996; RANGEL-BETTI, 1998).

Nessa direção, embora não enfocando necessariamente o profissional de educação física atuante fora da escola, existem alguns ensaios e pesquisas que revelam a importância de se reconhecer a complexidade de recursos diversos que não apenas o conhecimento científico para o desenvolvimento de programas de educação física (LOVISOLO, 1996; RANGELBETTI, 1998; SORIANO, 2003).

Lovisolo (1996) sugeriu que mais do que a validade e o volume do conhecimento científico empregado, em seus termos, pelo educador físico, o que se destacará de fato será o alcance de objetivos sociais, para os quais serão combinados conhecimentos, técnicas e tecnologias, resultando em programas que, intencionalmente ou não, estarão realizando objetivos e valores políticos, sociais, estéticos, entre outros. Por conta dessa combinação de conhecimentos, técnicas e tecnologia, balizados pelos valores e objetivos sociais, o autor apregoa que o profissional de educação física opera como um bricoleur, pois é no cotejo desses elementos diante de uma determinada demanda, que se dá o "produto intelectual de sua atividade" (p.20), porém "nem a definição dos valores orientadores da intervenção nem a seleção das disciplinas ou conhecimentos auxiliadores são decisões científicas" (p.21)

Na direção de apontar a expansão do mercado de trabalho na área e, conseqüentemente, o aumento de variáveis com as quais os profissionais de educação física têm de lidar, bem como a complexidade de suas interações, Godbout, Samson \& Bérubé (1992) levantam algumas implicações diretas associadas com esse crescimento das possibilidades de intervenção profissional. Esses autores colocam, ainda, que o considerável aumento do número de 
pessoas envolvidas nos programas de atividade física tem resultado crescimento, diversificação e refinamento dos serviços diretos e indiretos, que dão suporte ao planejamento e operacionalização de projetos organizacionais, provocando algumas diversificações nos papéis dos profissionais de educação física.

Precisamos reconhecer, no entanto, que apesar de recentemente regulamentada a educação física no Brasil, os dados acerca das variáveis da intervenção profissional carecem de indicativos e levantamentos significativos e mais precisos sobre as áreas e locais de atuação profissional, de modo que as mesmas confusões conceituais e áreas excessivamente abrangentes ainda permanecem ${ }^{3}$.

O caráter transitivo que reveste as intervenções profissionais, de maneira geral, e educação física, especialmente é, sem dúvida, o mais provocativo desafio. Nesse sentido, para compreender aquilo que compõe as intervenções/ações profissionais, ou seja, o conhecimento "formalizado", as estratégias de ação e as representações (SORIANO, 2004), faz-se necessário reconhecer a natureza multidimensional da subjetividade do profissional, que vai imprimir no seu modo de agir elementos em comum dentro de um grupo, conforme as inscrições culturais, e que, ao mesmo tempo, vão se diversificar conforme sua inserção social, política, econômica e educacional.

\section{Considerações Finais}

Apesar de haver diferenças significativas entre os aportes teóricos que procuram estudar e promover a compreensão da noção de competência, todos eles, críticos ou assertivos, parecem não se diferenciar naquilo que é básico a esta noção: o entendimento da competência como uma capacidade de ação para a qual

${ }^{3}$ Ver na atual CBO (classificação brasileira de ocupações), a reformulação encaminhada pelo CONFEF. Disponível em<http://www.mtecbo.gov.br>. Acessada em 10 out. 2002.

Movimento, Porto Alegre, v.12, n. 01, p. 175-195, janeiro/abril de 2006. 
são mobilizados alguns recursos, tais como conhecimentos, qualidades, habilidades e aptidões que possibilitam o estudo, a investigação, a reflexão, a discussão, mas fundamentalmente, a decisão sobre o que se refere à intervenção profissional.

As perspectivas escolhidas aqui proporcionam algumas possibilidades instigantes para se estudar e refletir a intervenção profissional em Educação Física:

a) os saberes eruditos ou acadêmicos científicos são colocados como um dentre outros elementos para uma intervenção profissional competente;

b) a necessidade de compreensão da existência de agentes multiinfluenciadores no modo de operar uma resposta profissional;

c) assumir para noção de competência um caráter formativo, pois literalmente na constituição de seu processo é possível avaliar como vai se compondo a intervenção do profissional;

d) as transformações que as intervenções sofrem devem ser assumidas como perenes, de modo que a proposição de algum tipo de lista de atributos, favoreceria uma visão "congelada", quase que fotográfica, das respostas profissionais.

Obviamente, a ênfase ou intensidade de mobilizar um ou outro recurso vai depender da relação de construção que o profissional mantiver, pois ela estará vinculada muito mais à subjetividade, do que muitos pesquisadores supunham ou gostariam de admitir, visto que entram em cena nesse processo de construção: a identidade, a imagem de si mesmo, a sua inserção nas relações sociais e o seu itinerário pessoal ou familiar.

Não obstante essa dificuldade, toda atividade de trabalho tem, em algum grau, a possibilidade de ser descrita. Assim, a avaliação da competência, a partir da dinâmica dos elementos que compõe a atuação, implicaria uma referência, tanto para balizar a real importância do conhecimento "formalizado", como

Movimento, Porto Alegre, v.12, n. 01, p. 175-195, janeiro/abril de 2006. 
também, evidenciaria a manifestação de outros tipos de componentes contidos numa intervenção competente. Em decorrência dessa múltipla perspectiva, consideramos a necessidade de observar o paradoxo sobre o delineamento de seus elementos, pois apesar de ser um exercício essencial é, simultaneamente, insolúvel, não determinístico.

Nesse caso, o emprego da noção de competência, pode permitir, o discernimento daquilo que orienta o processo de tomar de decisão do profissional de educação física, inclusive no entendimento ou ênfase discricionária de suas decisões, ou seja, (a) que valores orientam sua intervenção, (b) o quanto se pautam em sua rede relações profissionais, (c) a dimensão das influências interprofissionais.

Até aqui, colocadas essas observações, temos que, para estudar a intervenção profissional por meio da noção de competência, balizando-nos pelas limitações e desafios de seus usos, há necessidade de enfrentar incertezas, imprecisões, ambigüidades e contradições de um fenômeno complexo ${ }^{4}$

A partir de então, fica clara para nós a impossibilidade de se criar um sistema ou protocolo fixo de avaliação para aferir uma intervenção competente, seja de maneira geral, ou mesmo, particularmente em Educação Física. Mas ainda insistimos na necessidade de se compreender as implicações de alguns aspectos no "agir" profissional. Para isso, consideramos finalmente, a partir do exercício de reflexão proporcionado pela realização desse ensaio, partilhar o reconhecimento da complexidade do intervir/agir profissional "[...] não só como dimensão pessoal da experiência de cada um, mas como dimensão coletiva e profissional" (Perrenoud, 2001, p.47).

${ }^{4}$ Aqui ousamos nos orientar e aproximar das reflexões de Morin sobre a necessidade de reconhecimento daquilo que subjaz e permeia a constituição de um fenômeno observado de quem observa, em suas características biológicas, físicas e sobretudo antropológicas.

Movimento, Porto Alegre, v.12, n. 01, p. 175-195, janeiro/abril de 2006. 
Limits and challenges for the study of the professional intervention in physical education based on the notion of competence

Abstract: The purposes of this work are to discuss and problematize the notion of competence and the complex elements linked to the intervention of the Physical Education professional, in non-educational environments. As for that, some notes were considered about the caution one might have in dealing with the notion of competence in several theoretical bases. The transitive feature that pervades the professional interventions in general and, more specifically, the physical education is, absolutely, the most provocative challenge. In this sense, in order to understand what constitutes the professional interventions/actions in physical education, that is, the "formalized" knowledge, the strategies of action and the representations, it is necessary to recognize the multidimensional nature involved in the professional responses. Finally, it can be considered that the use of the notion of competence may enable the discernment of what guides the decision-making process of the physical education professional, including the understanding of discretionary emphasis of their decisions.

Key words: Competence. Professional Practice. Physical Education. 
Los límites y desafíos para el estudio de la intervención profesional en educación física basada en la noción de competencia

Resumen: Los propósitos de este trabajo son dis-

cutir y problematizar que la noción de competencia y los elementos complejos se unió a la intervención del profesional de Educación Físico, en los ambientes non-educativos. En cuanto a eso, algunas notas fueron consideradas sobre la cautela uno podría tener tratando con la noción de competencia en varias bases teóricas. El rasgo transitivo que satura las intervenciones profesionales en genera y, más específicamente, la educación física es, absolutamente, el desafío más provocativo. En este sentido para entender lo que constituye el intervenciones/acciones profesionales en la educación física, eso está, el conocimiento "formalizado", las estrategias de acción y las representaciones, es necesario reconocer la naturaleza multidimensional involucrada en las contestaciones profesionales. Finalmente, puede ser considerado que el uso de la noción de competencia puede permitir el proceso de decisión-fabricación del profesional de educación físico, incluso la comprensión en la comprensión del énfasis discrecional de sus decisiones.

Palabras-clave: Competencia. La Práctica profesional. Educación física.

\section{REFERÊNCIAS}

BECHER, T. The learning professions. Studies in higher education, v. 21, n.1 p.43-55, 1996.

BETTI, M. Por uma teoria da prática. Motus Corporis, v.3, n.2, p.73-127, 1996.

BURRAGE, Michael. De la educación práctica a la educación professional académica pautas de conflicto y adaptación en Inglaterra, Francia y Estados Unidos. In: ROTHBLATT, S.; WITTROCK B. La Universidad europea y americana desde 1800: Ias tres transformaciones de la Universidad moderna. Barcelona: Ediciones Pomares-Corredor, 1996. p.156-206

Movimento, Porto Alegre, v.12, n. 01, p. 175-195, janeiro/abril de 2006. 
DESAULNIERS, J. B. R. Formação, competência e cidadania. Educação \& Sociedade, ano XVIII, n.60, p.51-63, 1997.

DESAULNIERS, J. B. R. Introdução. In: (org.). Formação e trabalho e competência. Porto Alegre: Edipucrs, 1998. p.7-16.

FREIDSON, E. Renascimento do profissionalismo. São Paulo: Edusp, 1998.

GODBOUT, P.; SAMSON, J.; BÉRUBÉ, G. The service component of the physical activity sciences. In: BOUCHARD, C.; McPERSON, B. D.; TAYLOR, A. W. Physical activity sciences. Champaing: Human Kinetics Publishers, 1992. cap.16. p.131-137.

HOUAISS, A.; VILLAR, M. de S. Dicionário Houaiss da Língua Portuguesa. Rio de Janeiro: Objetiva, 2001.

LAWSON, H. A. Beyond positivism: Research, practice, and undergraduate professional education. Quest, n.42, p.161-183, 1990.

LAWSON, H. A. International changes and challenges: their import for new models for practice. Quest, v.47, n.4, p.411-426, 1995.

MANFREDI, S. M. Trabalho, qualificação e competência profissional: das dimensões sociais e políticas. Educação e Sociedade, ano XIX, n.64, p.13-49, 1998.

MEGHNAGI, S. A competência profissional como tema de pesquisa. Educação e Sociedade, ano XIX, n.64, p.50-86, 1998.

MORIN, E. Ciência com consciência. Sintra: Publicações Europa-América, 1982. PERRENOUD, P. Ensinar: agir na urgência, decidir na incerteza. Porto Alegre: ArtMed, 2001a.

RANGEL-BETTI, I. C. A. Educação física e o ensino médio: analisando um processo de aprendizagem profissional. São Carlos, 1998. Tese (Doutorado) - Faculdade de Educação, Universidade Federal de São Carlos.

ROPÉ, F.; TANGUY, L. Introdução. In: (orgs). Saberes e competências: o uso de tais noções na escola e na empresa. Campinas: Papirus, 1997. p.15-24.

SCHWARTZ, Y. Os ingredientes da competência: um exercício necessário para uma questão insolúvel. Educação \& Sociedade, ano XIX, n.65, p.101-139, 1998.

SORIANO, J. B. A constituição da intervenção profissional em educação física: interações entre o conhecimento "formalizado" e a noção de competência. Campinas, 2003. 240p. Tese (Doutorado) - Faculdade de Educação Física, Universidade Estadual de Campinas.

SORIANO, J. B. A constituição da intervenção profissional em educação física: Interações entre o conhecimento "formalizado" e as estratégias de ação. Revista Brasileira de Educação Física e Esporte, v.18, n.4, p.315-332, 2004

Movimento, Porto Alegre, v.12, n. 01, p. 175-195, janeiro/abril de 2006 
STROOBANTS, M. A visibilidade das competências. In: ROPÉ, F.; TANGUY, L. (orgs). Saberes e competências: o uso de tais noções na escola e na empresa. Campinas: Papirus, 1997. p.135-166.

STROOBANTS, M. Trabalho e competência; recapitulação crítica das pesquisas sobre saberes. In: DESAULNIERS, J. B. R. (org.). Formação e trabalho e competência. Porto Alegre: Edipucrs, 1998. p.17-46.

TANGUY, L. Competências e integração social na empresa. In: ROPÉ, F.; TANGUY, L. (orgs). Saberes e competências: o uso de tais noções na escola e na empresa. Campinas: Papirus, 1997. p.167-200.

TANI, G. Cinesiologia, educação física e esporte: ordem emanente do caos na estrutura acadêmica. Motus Corporis, v.3, n.2, p.9-50, 1996.

TARDIF, M.; GAUTHIER, C. O professor como "ator racional": que racionalidade que saber, que julgamento? In: Perrenoud, P.; Paquay, L.; Altet, M.; Charlier, E. Formando professores profissionais. Quais estratégias? Quais competências? 2.ed. Porto Alegre: Artmed, 2001. p.177-201.

TORSTENDAHL, Rolf. La transformación de la educación profesional en el siglo XIX. In: ROTHBLATT, S; WITTROCK, B. La Universidad europea y americana desde 1800: las tres transformaciones de la Universidad moderna. Barcelona: Ediciones Pomares-Corredor, 1996. p.121-155.

Recebido em: 14/03/2005 Aprovado em: 09/03/2006

Jeane Barcelos Soriano Centro de Educação Física e Esporte - UEL Grupo de Estudos sobre a Intervenção do Profissional de Educação Física - GEIPEF

Caixa Postal 6001 86051-990 - Londrina - PR (43) 3371-4238

soriano@sercomtel.com.br

Movimento, Porto Alegre, v.12, n. 01, p. 175-195, janeiro/abril de 2006. 